system, the decrease in mean arterial pressure averaged 39.9 per cent, and was chiefly a result of a 30.4 per cent reduction in calculated peripheral resistance, the cardiac output being reduced by 13.6 per cent only. In twenty DS episodes recorded after sympathectomy and sinoaortic deafferentation, the decrease in mean arterial pressure was halved, averaging 20.0 per cent; the decrease in calculated peripheral resistance was reduced even more, averaging $9 \cdot 6$ per cent. Differences in pressure and resistance changes between intact and sympathectomized eats were both highly significant statistically $(P<0.001)$. On the other hand, the decrease in cardiac output was of similar magnitude in sympathectomized and intact cats ( $10 \cdot 8$ compared with 13.6 per eent).

In sympathectomized cats a few episodes of DS were accompanied by falls in cardiac output so large as to cause signs of cerebral anoxia. This is confirmation that changes in cardiac output during DS are not affected by sympathectomy. There was still a decrease in cardiac output and cerebral anoxia still occurred in sympathectomized animals after blockade of the vagal innervation to the heart by methylatropine (1 $\mathrm{mg} / \mathrm{kg}$ given intravenously).

It can be concluded that the haemodynamic pattern most usually observed during DS is greatly modified by sympathectomy. The decrease in arterial pressure is markedly reduced, and the decrease in resistance becomes a component of much lesser importance. The principal cardiovascular action of DS therefore seems to be a dilatation of resistance vessels, resulting from a fall of
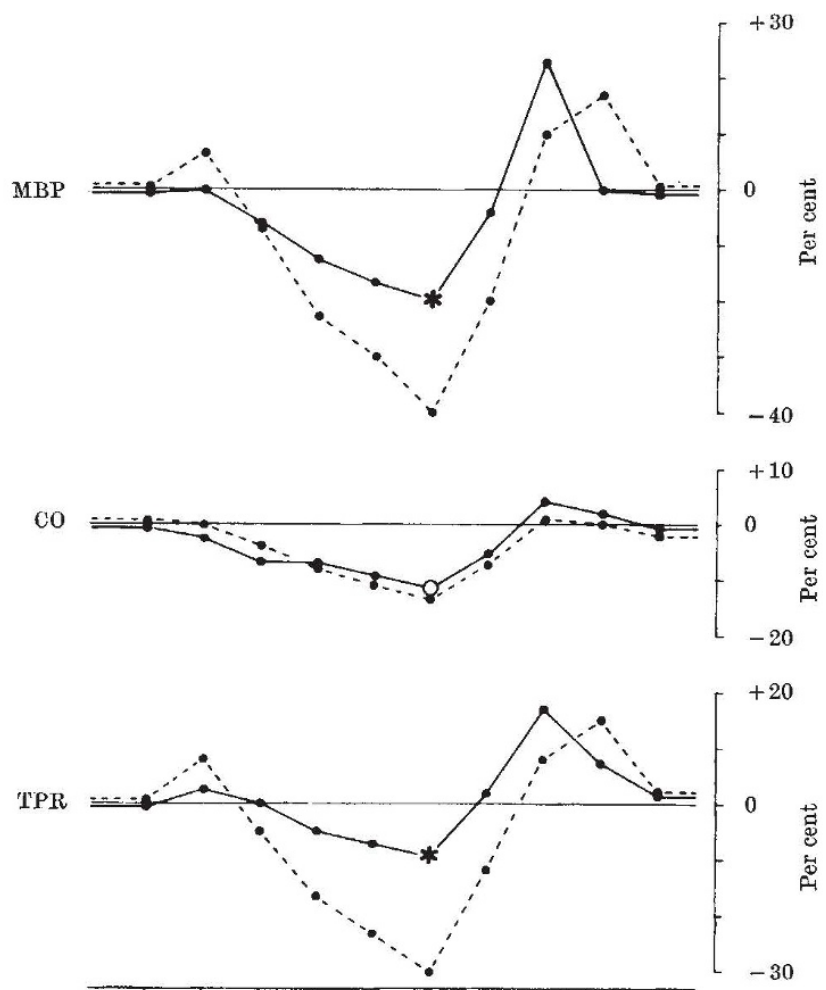

$\begin{array}{llllllllll}\mathrm{C} & 1 & 2 & 3 & 4 & 5 & 6 & \mathrm{~A} & \mathrm{ADS} & \mathrm{SS}\end{array}$

Fig. 2. Changes in mean arterial pressure (MBP), cardiac output (CO) and total peripheral resistance (TPR) during forty episodes of desynchronized sleep in cats with intact sympathetic system (-.) and during twenty episodes recorded after total sympathectomy $(-\vec{C})$. Ang animals with sino-aortic deafferentation. Mean values at the following periods indicated on the abscissas: C, Control during synchronized tension; ; 3 , increase of hypotension: 4 , further increase of hypotension 5 , lowest pressure values during DS; 6 , toward the end of DS; A arousal from DS; ADS, 1 min after A; sS, reappearance of synchronized sleep. On the ordinates all cardiovascular measurements expressed as percentage changes referred to $\mathrm{C}$. Statistically significant differences between values measured at point 5 in animals with intact sympathetic system and after sympathectomy are indicated by crosses $(P<0.01)$ or asterisks $(P<0 \cdot 001)$. Hollow circles indicate non-significant differences $(P>0 \cdot 05)$ sympathetic vasoconstrictor tone, an interpretation supported by recent electrophysiological evidence ${ }^{7,8}$. On the other hand, the decrease in cardiac output during DS, usually rather small but sometimes so large as to lead to cercbral anoxia, is independent of changes in sympathetic activity, and does not result from vagal influences on the heart. This decrease in cardiac output is not therefore caused by influences mediated through the autonomic nervous system, and seems to be mediated through a non-neural mechanism, the nature of which is unknown. The role of factors such as coronary underperfusion and respiratory changes should be tested experimentally.

This work was sponsored by the US Air Force Office of Scientific Research, through the European Office of Aerospace Research, US Air Force, and by the Consiglio Nazionale delle Ricerche.

Grorgio Baccelti

MaUrizio Guazzi

Giuseppe Mancia

AlBerto ZaNCHett

Istituto di Ricerche Cardiovascolari,

University of Milan.

Received April 8, 1969.

'Candia, O., Favale, E., Giussani, A., and Rossi, G. F., Arch. Ital. Biol., 100, 216 (1962).

${ }^{2}$ Guazzi, M., and Zanchetti, A., Science, 153, 397 (1965). Kumazawa, T., Baccelli, G., Guazi, M., Mancia, G., and Zanchetti, A.,
Experientia,23, 1021 (1967)

${ }^{4}$ Guazzi, M., Baccelli, G., and Zanchetti, A., Amer. J. Physiol., 214, 969 (1968).

${ }^{5}$ Guazzi, M., Mancia, G., Kumazawa, T., Baccelli, G., and Zanchetti, A., Cardiovascular Res., 2,265 (1968).

6 Cannon, W. B., Newton, H. F., Bright, E. M., Menkin, V., and Moore, R. M., Amer. J. Physiol., 89, 84 (1929).

${ }^{7}$ Iwamura, Y., Uchino, Y., Ozawa, S., and Torii, S., Proc. Japan Acad., 42, $837(1966)$.

- Baust, W., Weidinger, H., and Kirchner, F., Arch. Ital. Biol., 106, 379 (1968).

\section{Cultivated Plants and the Kon-Tiki Theory}

Pickersgill and Bunting say ${ }^{1}$ that the natural dispersal of the sweet potato is severely limited, for many varieties seldom flower and set seed even more rarely. Although this may be true for the United States ${ }^{2}$ and Japan ${ }^{3}$, sweet potatoes are recorded to set seed abundantly in St Vincent ${ }^{4}$ and only one in 100 clones failed to flower in $\mathrm{Java}^{5}$.

Although floral differences were not used to distinguish eighty-eight West Indian clones because of the short duration and irregularity of flowering in many of them ${ }^{6}$, over $7 \mathrm{yr}$ I noted that most varieties flowered and set seed in Trinidad. The breeding programme at the University of the West Indies initially depended on more than 1,000 seedlings raised from open-pollinated seeds collected from twenty varieties. Because the sweet potato is usually self sterile and cross-incompatibility is frequent, seed is usually only found in plots of mixed varieties such as are grown on small-holdings particularly in the Windward and Leeward Islands.

22 Golf Crescent, Troon.

\section{H. J. Gooding}

Received April 23, 1969.

${ }^{1}$ Pickersgill, B., and Bunting, A. H., Nature, 222, 225 (1969).

${ }^{2}$ Miller, J. C., J. Hered., 28, 347 (1937).

${ }^{3}$ Cuthbertson, R. H., and Boulware, J. H., GHQ Supreme Command for Allied Powers (Japan) Natural Resources Section Rep. No. 145 (1951).

- Rep. Dep. Agric. St Vincent, 9 (1919).

${ }^{3}$ Van Schreven, A. C., Pember. Balai Besar Penjel. Pertan. Bogor. No. 139, 44 (1954).

- Gooding, H. J., Emp. J. Exp. Agric., XXXII, No. 128, 279 (1964).

Professon Bunting writes: Dr Pickersgill and I were not aware of the work in Java and St Vincent, to which Gooding refers: we are glad to have the references. We 